\title{
Prevalence and genetic diversity of fig mosaic virus isolates infecting fig tree in Iran
}

\author{
S. DANESH-AMUZ, F. RAKHSHANDEHROO*, S. REZAEE
}

Department of Plant Pathology, College of Agriculture and Natural Resources, Science and Research Branch, Islamic Azad university, Tehran, Iran, P. O. Box 14515-775

Received November 29, 2013; accepted August 5, 2014

\begin{abstract}
Summary. - Commercial and outdoor fig orchards in four Iranian provinces were surveyed for the incidence of fig mosaic virus (FMV), fig leaf mottle associated virus 2 (FLMaV-2) and fig mild mottle associated virus (FMMaV) from March 2011 to October 2012. A total of 350 asymptomatic and symptomatic fig samples were collected and tested by dot-immunobinding assay (DIBA) for the fig mosaic disease (FMD) using a polyclonal antiserum. According to DIBA results, FMD was present in $73 \%$ of the collected symptomatic samples from all visited regions. Samples with positive reactions in DIBA were then analyzed by RT-PCR using with specific primers. PCR results showed that about $14.8 \%$ of the FMD-positive samples from three inspected provinces are infected with at least one virus. FMV was the most widely spread virus (14\%) followed by FLMaV-2 (1.5\%), whereas FMMaV was not found. Phylogenetic analysis of the glycoprotein nucleotide and amino acid sequences of known FMV isolates showed two independent groups with high bootstrap values, with all Iranian isolates distinctly clustered in group I, subgroup IA beside those reported in Turkey. Nucleotide diversity was high within but low between different selected geographic regions and except for Europe, nucleotide distance within geographic regions was low. Statistical analyses indicated a correlation between the genetic structure of the FMV isolates and the geographical origin of isolation. Our analyses suggested that the FMV population is in a state of increase following a bottleneck or founder event in Iran.
\end{abstract}

Keywords: Ficus carica; phylogeny; genetic diversity; RT-PCR; sequencing

\section{Introduction}

Cultivated fig (Ficus carica L.), an important tree plant of the family Moraceae, is one of the oldest domesticated crops in Iran and the world. Most of the fig cultivars have arisen by the process of traditional selection in Iran. Fig tree was supposed to have entered into Iran and other Asian countries form the East Mediterranean countries like Turkey,

"Corresponding author. E-mail: rakhshandehroo_fa@srbiau.ac.ir; phone: +98-912-4786687.

Abbreviations: DIBA = dot-immunobinding assay; FLMaV-2 = fig leaf mottle associated virus 2; FMD = fig mosaic disease; FM$\mathrm{MaV}$ = fig mild mottle associated virus; FMV = fig mosaic virus; HSP70 = heat shock-protein 70; Gp = glycoprotein; TSWV = tomato spotted wilt virus where its genetic resources are still available as wild fig, and is considered to be the origin of this plant (Condit, 1955). Fig mosaic disease is the most common virus disease of fig plants. The etiology of FMD is still under investigation, but it was found that it is caused by one or more viruses from a complex of several viruses infecting fig trees in different fig growing countries. This complex comprises 16 different viruses belonging to different genera including: Bunyaviridae, Caulimoviridae, Closteroviridae, Flexiviridae, Partitiviridae, and Tymoviridae (Elbeaino et al., 2006, 2007a, 2009, 2010, 2011a,b; Gattoni et al., 2009).

FMD causes many disorders in fig trees, leading to poor fruit quality, reduction of productivity, shortening of the tree life and it affects the tree growth of many commercial cultivars (Walia et al., 2009; Martelli, 2011). Little is known about the etiology of FMD and its transmis- 
sibility (Caglayan et al., 2010). Fig mosaic virus (FMV) belongs to the recently established the genus Emaravirus of the family Bunyaviridae (Adams and Carstens, 2012). It is a six partite negative-sense RNA virus that is recognised as the main viral agent involved in the fig mosaic disease (Elbeaino et al., 2012). Like other emaraviruses, the genome of FMV contains RNAs with monocistronic ORF, each of which codes for a single protein (Elbeaino et al., 2012). Genomic ssRNAs range in size from $7.09 \mathrm{~kb}$ to $1.212 \mathrm{~kb}$ (Elbeaino et al., 2012; Walia and Falk, 2012). During 2006-2010, the incidence of FMD increased in the western and southern provinces of Iran, causing significant yield losses. The cause of the sudden emergence of FMD was undetermined until our previous research that showed the existence of FLV-1, FLMaV-1, and FMV associated with the mosaic-affected fig trees throughout the gardens in the mentioned regions of Iran (Shahmirzaie et al., 2012). The objective of the present study was to provide new data about existing FMV strains and their genetic diversity in the most important fig plantations in central, eastern and northern regions of Iran.

\section{Materials and Methods}

Sample collection and field observations. Samples were collected from commercial and outdoor fig gardens in 4 provinces of Iran, including Alburz (in northern part of Iran), Khorasan-Razavi (In east), Mazandaran (In north) and Tehran (in the centre), from March 2011 to October 2012 (Table 1). In total, 66 gardens in twenty two cities were randomly surveyed and 350 samples were collected from symptomatic (256 samples) and asymptomatic (94 samples) leaves. A sample consisted of two young leaves per plant. DIBA test was done with the universal polyclonal antibodies (Istituto Agronomico Mediterraneo di Bari, Via Ceglie 9, 70010 Valenzano (BA), Italy) against viruses that are involved in FMD. Samples with positive reactions in DIBA were then inspected by RT-PCR for the presence of FLMaV-2, FMV and FMMaV. Healthy fig plants obtained by tissue culture were used as negative controls.

$R N A$ isolation and RT-PCR. Fig samples that positively reacted with the specific polyclonal antibody against FMD in DIBA and proved to be infected with fig mosaic viral complex were further subjected to RT-PCR. Using the GF-TR-100 RNA Isolation mini Kit (Vivantis, Malaysia), total ribonucleic acid was extracted from

Table 1. Incidence of FMV and FLMaV-2 infections in symptomatic fig samples collected from fig orchards in Iran

\begin{tabular}{|c|c|c|c|c|c|c|c|c|c|c|}
\hline \multirow{2}{*}{ Province } & \multirow{2}{*}{ Region } & \multirow{2}{*}{$\begin{array}{c}\text { Tested trees } \\
\text { No }\end{array}$} & \multicolumn{2}{|c|}{ Infected trees ${ }^{\mathrm{a}}$} & \multicolumn{2}{|c|}{ FMV } & \multicolumn{2}{|c|}{ FMMaV } & \multicolumn{2}{|c|}{ FLMaV-2 } \\
\hline & & & No & $\%$ & No & $\%$ & No & $\%$ & No & $\%$ \\
\hline \multirow{4}{*}{ Alburz } & Bilaghan & 4 & 0 & 0 & 0 & 0 & 0 & 0 & 0 & 0 \\
\hline & Fardis & 34 & 0 & 0 & 0 & 0 & 0 & 0 & 0 & 0 \\
\hline & Hashtgerd & 12 & 0 & 0 & 0 & 0 & 0 & 0 & 0 & 0 \\
\hline & khozancola & 2 & 0 & 0 & 0 & 0 & 0 & 0 & 0 & 0 \\
\hline \multirow[t]{3}{*}{$(0)^{\mathrm{b}}$} & Mahdasht & 8 & 0 & 0 & 0 & 0 & 0 & 0 & 0 & 0 \\
\hline & Porkan & 6 & 0 & 0 & 0 & 0 & 0 & 0 & 0 & 0 \\
\hline & Zibadasht & 8 & 0 & 0 & 0 & 0 & 0 & 0 & 0 & 0 \\
\hline \multirow{4}{*}{ Khorasan- Razavi } & Bardeskan & 8 & 2 & 25 & 2 & 25 & 0 & 0 & 2 & 25 \\
\hline & Ghochan & 2 & 0 & 0 & 0 & 0 & 0 & 0 & 0 & 0 \\
\hline & Kashmar & 4 & 0 & 0 & 0 & 0 & 0 & 0 & 0 & 0 \\
\hline & Mashhad & 28 & 4 & 14.3 & 4 & 14.3 & 0 & 0 & 0 & 0 \\
\hline \multirow[t]{4}{*}{$(14.8)$} & Neshaboor & 4 & 0 & 0 & 0 & 0 & 0 & 0 & 0 & 0 \\
\hline & Shandiz & 4 & 0 & 0 & 0 & 0 & 0 & 0 & 0 & 0 \\
\hline & Torghabeh & 4 & 2 & 50 & 2 & ${ }^{c} 50$ & 0 & 0 & 0 & 0 \\
\hline & Amol & 10 & 2 & 20 & 0 & 0 & 0 & 0 & 2 & 20 \\
\hline \multirow[t]{2}{*}{ Mazandaran } & Babolsar & 2 & 0 & 0 & 0 & 0 & 0 & 0 & 0 & 0 \\
\hline & Baijan & 8 & 4 & 50 & 4 & 50 & 0 & 0 & 0 & 0 \\
\hline \multirow[t]{2}{*}{ (25) } & Fereidon Kenar & 10 & 3 & 30 & 3 & 30 & 0 & 0 & 0 & 0 \\
\hline & Ramsar & 10 & 1 & 10 & 1 & 10 & 0 & 0 & 0 & 0 \\
\hline \multirow[t]{2}{*}{ Tehran } & Islamshahr & 8 & 0 & 0 & 0 & 0 & 0 & 0 & 0 & 0 \\
\hline & Tehran & 58 & 17 & 29.3 & 17 & 29.3 & 0 & 0 & 0 & 0 \\
\hline$(22.7)$ & Varamin & 22 & 3 & 13.6 & 3 & 13.6 & 0 & 0 & 0 & 0 \\
\hline Total Infection & & 256 & 38 & & 36 & & 0 & 0 & 4 & \\
\hline Mean Infection & & & & 14.8 & & 14 & & 0 & & 1.5 \\
\hline
\end{tabular}

${ }^{\mathrm{a}}$ Data obtained by RT-PCR for FMV. ${ }^{\text {PPercentage of FMV infection in each province. }}{ }^{\mathrm{c}}$ The highest incidence rate of FMV in each surveyed province is shown in bold. 
$100 \mathrm{mg}$ of fig leaf tissues according to the manufacturer's instructions. First-strand cDNA synthesis was carried out using M-MuLV reverse transcriptase (MBI, Fermentas, Germany) according to the manufacturer's instructions in a $20 \mu \mathrm{l}$ reaction mixture. For the detection of FLMaV-2, FMMaV, and FMV three sets of virus-specific primers were used in RT-PCR (Table 3 ). The PCR was carried out with $2.5 \mu \mathrm{l}$ cDNA in a total volume of $25 \mu \mathrm{l}$ containing $1.5 \mathrm{mmol} / \mathrm{l}$ $\mathrm{MgCl}_{2}, 0.2 \mathrm{mmol} / \mathrm{l} \mathrm{dNTPs}, 0.3 \mu \mathrm{mol} / \mathrm{l}$ of each primer, and 1unit of Taq DNA polymerase (Cinnagen, Iran). Amplifications were carried out in a thermocycler (Eppendorf, Hamburg, Germany) using an initial denaturation at $94^{\circ} \mathrm{C}$ for $4 \mathrm{~min}$, followed by 35 cycles at $94^{\circ} \mathrm{C}$ for $30 \mathrm{sec}, 50$ to $55^{\circ} \mathrm{C}$ for $35 \mathrm{sec}, 72^{\circ} \mathrm{C}$ for $45 \mathrm{sec}$, and a final incubation at $72^{\circ} \mathrm{C}$ for $7 \mathrm{~min}$. Primers were synthesized by MWG Biotech (Germany). Amplification products were analyzed by electrophoresis in $1 \%$ agarose gel containing ethidium bromide and visualized under UV light. Positive and negative samples were kindly supplied by Dr. Toufic Elbeaino (Bari, Italy).

Sequencing and phylogenetic analysis. The amplified PCR fragments were subjected to purification with the Ultra-Clean purification kit as described by the manufacturer (Fermentas Gene JET TM Gel Extraction Kit, Germany) and cloned into the pTZ57RT vector according to the manufacturer's instructions (MBI Fermentas, Germany). Escherichia coli DH5a were made competent according to Chung et al. (1989) and transformed with the ligation mix. Recombinant plasmids were sequenced using an ABI PRISMcc 3730XL automated sequencer (Macrogen Inc., Seoul, South Korea) and the sequence was deposited in GenBank (http://www.ncbi.nlm. nih.gov/ BLAST/). At least two clones of each selected isolate were sequenced. The GenBank Acc. Nos. of these sequences are listed in Table 2. For subsequent procedures, six FMV and the only detected

Table 2. Values from pairwise sequence comparisons based on BLAST analysis for heat shock-protein 70 (HSP70) and glycoprotein (Gp) genomic regions amongst FLMaV-2 and FMV isolates, respectively. Geographic origin and GenBank Acc. Nos. of FMV isolates used for sequence comparisons in this study

\begin{tabular}{|c|c|c|c|c|c|}
\hline \multirow[t]{2}{*}{ Virus } & \multirow[t]{2}{*}{ Acc. No. } & \multirow[t]{2}{*}{ Isolate } & \multirow[t]{2}{*}{ Origin } & \multicolumn{2}{|c|}{$\begin{array}{l}\text { Nucleotide (nt) and amino acid (aa) sequences } \\
\text { identity with reference }\end{array}$} \\
\hline & & & & $\mathrm{nt}$ & aa \\
\hline FMV & AB697828 & JS1 & Japan & 96 & 99 \\
\hline FMV & AB697829 & SB1 & Serbia & 90 & 100 \\
\hline FMV & FM864225 & GR10 & Italy & 100 & 100 \\
\hline FMV & FJ211074 & JJW & USA & 97 & 99 \\
\hline FMV & GU227409 & EI-D1-3 & Turkey & 90 & 99 \\
\hline FMV & GU227413 & EI-BS-15 & Turkey & 94 & 99 \\
\hline FMV & GU227415 & $\mathrm{D} 2$ & Turkey & 93 & 99 \\
\hline FMV & HQ703344 & CAN01 & Canada & 92 & 99 \\
\hline FMV & JQ173768 & Morguz1Gp2 & Turkey & 92 & 98 \\
\hline FMV & JQ173770 & SariZeybek3Gp4 & Turkey & 84 & 96 \\
\hline FMV & JQ173784 & NoiredeCoromb2Gp18 & Turkey & 92 & 96 \\
\hline FMV & JQ173799 & Sarilop1MKUCOGp33 & Turkey & 93 & 97 \\
\hline FMV & KC408932 & EMV- 1 & Iran & 89 & 100 \\
\hline FMV & KC408933 & EMV- 3 & Iran & 89 & 95 \\
\hline FMV & KC408934 & EMV- 4 & Iran & 88 & 98 \\
\hline FMV & KC408935 & EMF- S3 & Iran & 86 & 99 \\
\hline FMV & KC408936 & EMF- S9 & Iran & 88 & 99 \\
\hline FMV & KC408937 & FE-10 & Iran & 89 & 99 \\
\hline FLMaV-2 & FJ473383 & F3 & Italy & 100 & 100 \\
\hline FLMaV-2 & FN666271 & L2I & Turkey & 95 & 99 \\
\hline FLMaV-2 & FN668733 & IDB & Turkey & 96 & 99 \\
\hline FLMaV-2 & FN687736 & Alb12 & Albania & 99 & 99 \\
\hline FLMaV-2 & FN687737 & ALg3 & Algeria & 99 & 99 \\
\hline FLMaV-2 & FN687738 & LiB 53 & Lebanon & 96 & 99 \\
\hline FLMaV-2 & FN687743 & LiB 80 & Lebanon & 94 & 99 \\
\hline FLMaV-2 & FN687745 & Syr 8 & Syria & 98 & 99 \\
\hline FLMaV-2 & FN687747 & Tu58 & Tunisia & 92 & 99 \\
\hline FLMaV-2 & KC534878 & M2 & Iran & 93 & 99 \\
\hline $\mathrm{FMV}^{\mathrm{a}}$ & KC261957 & TSWV- 7 & South Korea & & \\
\hline
\end{tabular}

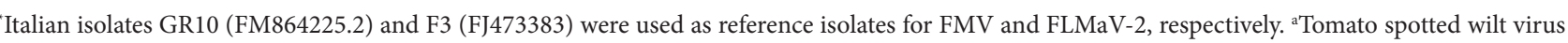
(TSWV) members of the genus Tospovirus used as an outgroup species. 
FLMaV-2, isolates were selected based on the geographical origin of the samples. Phylogenetic analysis of the selected Iranian isolates was conducted by comparing separately the $450 \mathrm{bp}$ nucleotides (nt) of the partial Gp gene of FMV with the comparable sequences of other corresponding isolates from GenBank using the BLAST (NCBI) program (Altschul et al., 1997).

Statistical tests of genetic differentiation, gene flow and estimation of genetic distance. Phylogenetic analyses were done by the neighbor-joining methods using MEGA 5.05 under the assumption of the substitution models proposed. The phylogenetic tree was constructed using the neighbor-joining algorithm (Saitou and Nei, 1987), p-distance method (Nei and Kumar, 2000) and bootstrap consisting of 1000 pseudo-replicates, and finally evaluated using the interior branch test method with Mega 5.05 software (Tamura et al., 2011). The nucleotide sequences were also translated to amino acid sequences and analyzed using the neighbor-joining method with Mega 5.05 program. Multiple alignment analysis was done by CLUSTAL W (Thompson et al., 1994). The nucleotide distance (average genetic distance between two randomly selected genetic variants) between pairs of sequences was estimated by the same software using the Kimura 2-parameter method (Kimura, 1980). The total populations of FMV isolates were divided into subpopulations based on different sampling regions. Within and between populations, diversities were estimated according to Nei (Nei, 1987) based on the T92+G model. The Tajima's statistic (Tajima, 1989) was also calculated to test the mutation neutrality hypothesis. Statistics as well as the natural selection pressure were calculated by the DnaSP 5.10 program (Librado and Rozas, 2009).

\section{Results}

According to DIBA results, FMD has occurred in collected symptomatic samples (73\%) from four provinces surveyed, including Alburz, Khorasan-Razavi, Mazandaran and Tehran. The incidences of FMD detected by DIBA differed between the surveyed provinces. FMD symptoms of mosaic restricted with a necrosis border, mottling and leaf malformations were observed in the surveyed fields. Due to mixed infections, it was difficult to identify the symptoms of a particular virus in the garden.

RT-PCR was done using as template symptomatic samples from infected fig trees (256 samples), which positively reacted with the anti-FMD antiserum in the DIBA test. Infection of the Iranian fig trees with FLMaV-2 and FMV, but not FMMaV, was confirmed by RT-PCR. PCR amplification of the FLMaV-2 and FMV genome fragments with the primers specific for the HSP70 and glycoprotein genes yielded the expected $360 \mathrm{bp}$ and $c a .468 \mathrm{bp}$ amplification products. No PCR products were amplified from healthy plants.

Of 256 samples with positive reaction to FMD antiserum in DIBA assay, 38 (14.8\%) contained plants infected by at least one of detected viruses when tested by RT-PCR. According to RT-PCR results, FMV was the prevailing virus (14\%), followed by FLMaV-2 (1.5\%). FLMaV-2 and FMV relative incidence varied among the geographical regions they were found. FLMaV-2 was found in the eastern and northern regions, whereas FMV was detected in the central, northern and eastern parts of Iran. Mazandaran province had the highest prevalence of infection (25\%), followed by Tehran $(22.7 \%)$ and Khorasan-Razavi (14.8\%) districts. Among the viruses, FMV was detected most frequently in visited regions, it was found in samples collected from Baijan, Bardeskan, Fereidon Kenar, Mashhad, Ramsar, Tehran, Torghabeh and Varamin districts with infection rates of $10 \%$ to $50 \%$ (Table 1). Highest incidence of FMV was found in Tehran province $(22.7 \%$ ) (Table 1 ). FLMaV-2 was detected in Bardeskan and Amol districts with infection rates of 25 and $20 \%$, respectively. It was detected in mixed infection with FMV in $0.8 \%$ of the collected samples. FLMMaV was not detected in any of tested samples.

The sequences reported in this paper were submitted to GenBank under the Acc. Nos. KC408932-KC408937 for FMV and KC534878 for FLMaV-2. Accessions related to the different provinces, where the viruses occurred in Iran, include: Mazandaran (KC408935, KC408936, and KC534878); Mashhad (KC408933 and KC408934) and Tehran (KC408932 and KC408937). Pairwise nucleotide comparison of Iranian FMV isolates showed low levels of divergence amongst them. On the basis of the BLAST analysis and sequence alignments, the nucleotide (nt) and amino acid (aa) sequence identities of the Gp gene of six Iranian FMV isolates ranged from 90 to $100 \%$ and 95 to $100 \%$, respectively. Obtained Iranian FMV sequences were related to the reference FMV nucleotide sequences (Acc. No. FM864225.2) with more than $86 \%$ and 95\% identities at the nucleotide and amino acid levels, re-

Table 3. List of primers used in RT-PCR for fig viruses detection

\begin{tabular}{|c|c|c|c|c|c|}
\hline Viruses & Primers & Primer sequences $\left(5^{\prime}-3^{\prime}\right)$ & Amplified product (bp) & Target gene region & Reference \\
\hline \multirow{2}{*}{ FLMaV-2 } & F3-s & GAACAGTGCCTATCAGTTTGATTTG & \multirow{2}{*}{360} & \multirow{2}{*}{ HSP70 } & \multirow{2}{*}{$\begin{array}{c}\text { Elbeaino et al. } \\
(2007)\end{array}$} \\
\hline & F3-a & TCCCACCTCCTGCGAAGCTAGAGAA & & & \\
\hline \multirow{2}{*}{ FMMaV } & LM3-s & AAGGGGAATCTACAAGGGTCG & \multirow{2}{*}{311} & \multirow{2}{*}{ HSP70 } & \multirow{2}{*}{$\begin{array}{c}\text { Elbeaino et al } \text {. } \\
\qquad(2010)\end{array}$} \\
\hline & LM3-a & TATTACGCGCTTGAGGATTGC & & & \\
\hline \multirow{2}{*}{ FMV } & EMARV-GP-s & GGGTACATATGCGTCATTCTTG & \multirow{2}{*}{470} & \multirow{2}{*}{$\mathrm{Gp}$} & \multirow{2}{*}{$\begin{array}{c}\text { Walia et al. } \\
\text { (2009) }\end{array}$} \\
\hline & EMARV-GP-a & CGTTTGTCTTGGATCACAGCAA & & & \\
\hline
\end{tabular}


spectively (Table 2). BLAST analysis of one FLMaV-2 isolate from Iran (KC534878) disclosed 92-100\% and 99-100\% identities at the nucleotide and amino acid levels with nine other sequences for the HSP70 genomic region from the GenBank (Table 2).

Phylogenetic tree based on the Gp nucleotide sequence alignments showed that all the FMV isolates are closely related, but formed two distinctive groups, in which each group is divided into two subgroups (Fig. 1). The six Iranian representative FMV isolates were shown to belong to separate subgroups ( $a$ and $b$ ) in group I (Figs. 1 $a$ and $b$ ). Iranian isolates stood beside Turkish isolates (EI-D1-3 and EI-BS-15) in Subgroup IA. Global isolates including FMV isolates collected from different countries (Canada, Italy, Japan, Serbia, Turkey and USA) were categorized in subgroup IB. Geographical clustering was observed for Iranian isolates in subgroup IA, in which isolates EMF-S3 and EMF-S9 from Mazandaran province in the north of Iran were clustered separately (Fig. 1a).

The tree reconstructed from amino acid sequences clustered the FMV isolates into two main groups and two subgroups in Group I on the basis of the Gp genomic region (Fig. 1b). Sequences from Iran were distributed between subgroups A and B in group I and segregated according to the geographical origin. Isolates in subgroup IA (EF-10, EMF-S3, EMV-1, EMV-3, and EMV-4) originated from the central (Tehran), northern (Mazandaran) and eastern (Mashhad) parts of the country, whereas isolates in subgroup
IB (EMF-S9) was detected in the northern part of the country (Mazandaran) (Fig. 1b). To analyze whether selected FMV isolates from different geographical origins are genetically differentiated populations, statistical tests of population were done. The FMV populations were divided into three geographic subpopulations: 2 isolates from America (Canada and USA), 10 isolates from Asia (Iran, Japan and isolates reported from the southern regions of Turkey) and 6 isolates from Europe (Italy, Serbia and isolates detected from western regions of Turkey). Nucleotide distances of FMV within Asia, America and Europe were 0.099, 0.089 and 0.236, respectively. Distance between subpopulations (continents) was about 0.038 for isolates from the Americas and Asia, 0.045 between America and Europe and 0.062 between Europe and Asia. Nucleotide diversity was high within each subpopulation (a value of 0.125 ). The Tajima's D was calculated to test the mutation neutrality hypothesis. The statistics was significantly negative, giving a value of $-2.0788(\mathrm{P}<0.05)$, suggesting a strong negative or purifying selection.

\section{Discussion}

This study showed the natural incidence and occurrence of FLMaV-2 and FMV in commercial and outdoor fig gardens in three provinces located in the central, northern and western regions of Iran. FLMaV-2 has been reported to infect fig trees in other countries throughout Africa, Asia,
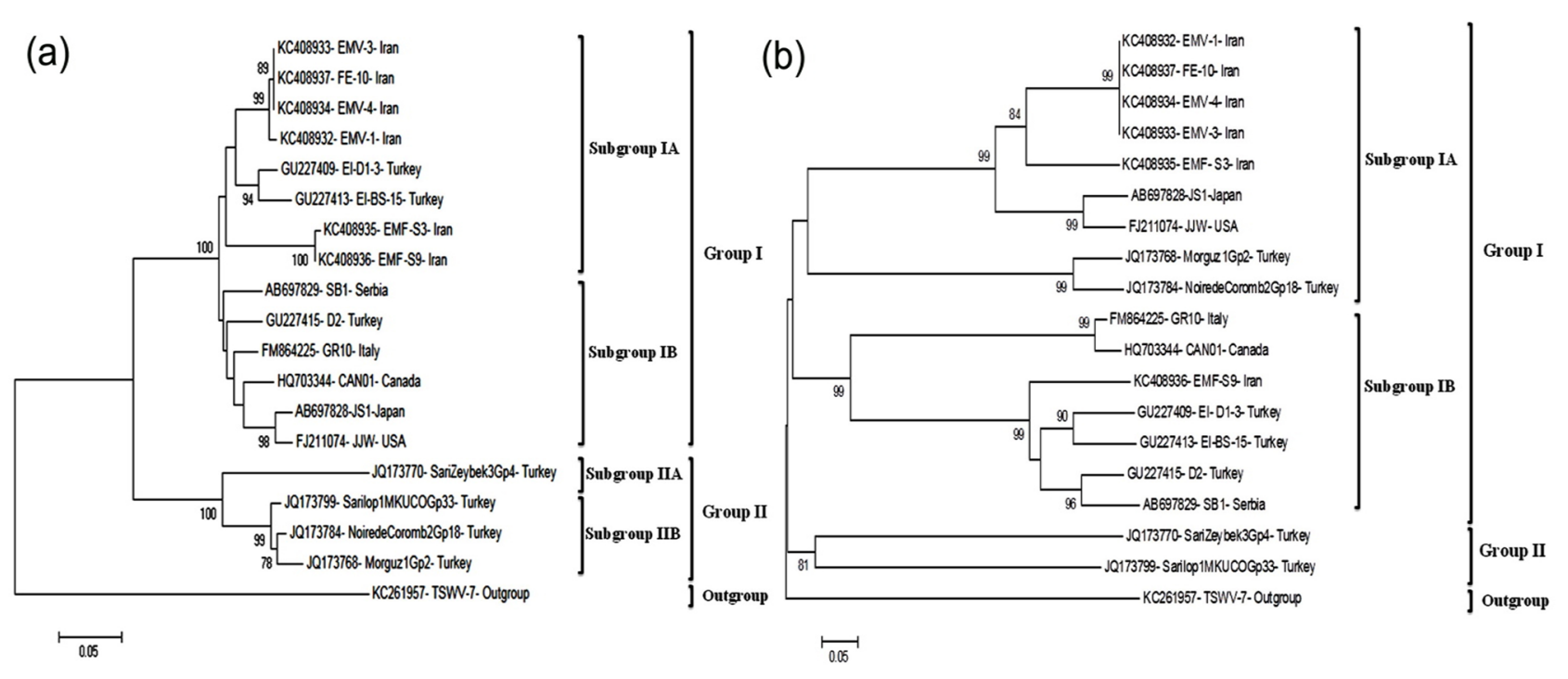

Fig. 1

Phylogenetic trees calculated from the nucleotide sequences (a) and amino acid sequences (b) of Gp-encoding region of fig mosaic virus by the neighbor-joining algorithm, based on calculations derived from the multiple alignment

Numbers at each node indicate bootstrap percentages based on 1000 replications. Only values $>50 \%$ are shown. The horizontal branch lengths are proportional to the genetic distance. The corresponding sequence of tomato spotted wilt virus (TSWV) was used as outgroup. 
and Europe (Elbeaino et al., 2007a,b; Caglar et al., 2011; Elbeshehy and Elbeaino, 2011). The detection of FLMaV-2 in mixed infection with FMV confirms the association of this virus in the etiology of FMD worldwide. Low levels of mixed infections with FLMaV-2 and FMV detected in Mazandaran $(0.7 \%)$ and Khorasan-Razavi $(0.7 \%)$ in this study is not a new finding. Similar mixed infections were also observed in fig trees in Turkey (Caglar et al., 2011). It was interesting that the incidence of FMV was considerably high (14\%) compared with the remaining tested viruses. It is possible that the FMV inoculum sources, such as infected fig propagative materials, were highly available to spread the virus in the visited regions. As the results above indicate, it can be concluded that FMV was the key virus affecting fig orchards in Iran. Therefore, efforts must be directed towards the control of the disease. The finding that FMV was predominant at sampling sites in Iran is in line with previous information about the cosmopolitan distribution of this virus (Caglar et al., 2011; Elbeaino et al., 2011c; Elbeshehy and Elbeaino, 2011; Martelli, 2011; Elci et al., 2012).

In this study, symptomatic fig samples from all surveyed provinces positively reacted with the universal polyclonal antibody against FMD by DIBA test, in which $14.8 \%$ of them proved to be infected with the FLMaV-2 or FMV by RT-PCR. Tested viruses were not recovered from symptomatic samples with FMD infection from Alburz province, indicating the presence of other viral agents involved in the FMD etiology in Iran. This may suggest that FMV does not play a significant role in the etiology of FMD in Iran. However, FMV has been recognised as main causal agent of fig mosaic disease (FMD) worldwide (Elbeaino et al., 2012). Whether very divergent strains of tested viruses are present in the country or other new viruses from different taxonomical groups are responsible for symptom expression in fig trees in the visited regions remains to be determined. In a recent study, fig fleckassociated virus (FFkaV) was reported in symptomatic fig samples from Alburz province (Nouri-Ale Agha et al., 2013). FMMaV was not detected in any of the tested fig samples collected from the central, eastern and northern regions of Iran in this study. Previous study has also shown that this virus is not present in the southern and western regions of Iran, suggesting that this virus is not involved in FMD in Iran (Shahmirzaie et al., 2012). This is in contrast with African, European and Mediterranean countries, where FMMaV was detected with the infection rates of 13.3 to $43.3 \%$ (Elbeaino et al., 2007a, 2010, 2011c, 2012; Elbeshehy and Elbeaino, 2011c; Elci et al., 2012).

In this study, we further analyzed the distribution and genetic variation of new FMV isolates in Iran with the aim to further our understanding of its population genetics and phylogenetic relationships. The phylogenetic relationship of all FMV isolates based on nucleotide sequence of the Gp gene showed segregation into two groups, in which each group divided into two distinct subgroups. Branching pattern based on differences in the geographical origin was found among the Iranian FMV isolates in group A, in which isolates EMF-S3 and EMF-S9 from north of Iran were separately clustered. Segregation according to the geographical origin on the basis of the amino acid sequences was also observed. Our conclusion is consistent with previous research on Tomato spotted wilt virus (TSWV), the other member of the family Bunyaviridae, showing that TSWV populations display geographical structuring attributed to founder effects (Tsompana et al., 2005). Our study of the Gp gene of 18 isolates indicates the possible existence of variants or strains in the FMV populations and there is at least one major population of FMV in different geographical regions of Iran. The relatively high diversity within each continent (0.125) suggests that the virus might have been long dispersed and accumulating its mutants for a considerable time in each continent. The fact that diversity between continents (0.056) is a little lower than diversity within continents suggests FMV population differentiation by the founder effect and a limited virus movement between continents. Except for Europe, which showed a 0.235 nucleotide distance, nucleotide distance was low within each studied geographic subpopulation, including Asia (0.099) and America (0.089), suggesting a spatial genetic stability among the FMV isolates in Asia and America and the existence of divergent isolates in Europe. The phylogenetic analysis also showed that the Turkish isolates were scattered in all phylogenetic groups and subgroups. The existence of divergent isolates in Europe as well as in Turkey, and the low divergence among the isolates from the rest of the world, suggested that European countries, especially Turkey, could be the origin of FMV and that this genotype might have disseminated worldwide. The phylogenetic analysis generated using the amino acid and nucleotide sequences of the FMV Gp gene showed that Iranian isolates are mostly similar to strains from Turkey, indicating the possible introduction of strains from Turkey into Iran. This is probably due to the exchange of infected propagative plant material. Tajima's $D$ test is based on the differences between the number of segregating sites and the average number of nucleotide differences. We estimated nucleotide polymorphisms in the FMV-Gp populations for each geographical group using their Gp nucleotide sequences by Tajima's D test. Tajima's D test results proved that Gp is evolving neutrally in Iran and worldwide. Negative values also indicated that the FMV population is in a state of increase following a bottleneck or founder event in Iran and that a decrease of the genetic variation by elimination of deleterious mutations by purifying selection maintained the population fitness. The glycoprotein is known to play an important role in maturation and assembly of virion in both plants and the vector by the attachment to receptors in the vector (Bandla et al., 1998). FMV population expansions may be attributed to the 
selection constraints, imposed to the Gp sequence by the vector, host plant or the environmental conditions that can be the main causes of the FMV variability observed in Iran. The study of the FMV population demography and genetic diversity lays the foundation for the development of strategies for the control of fig mosaic disease.

Acknowledgments. Many thanks are due to Dr. Toufic Elbeaino (Istituto Agronomico Mediterraneo di Bari, Via Ceglie 9, 70010 Valenzano (BA), Italy) for his invaluable advice during this study and for his assistance with the research materials and providing us with positive controls used.

\section{References}

Adams MJ, Carstens EB (2012): Ratification vote on taxonomic proposals to the International Committee on Taxonomy of Viruses. Arch. Virol. 157, 1411-1422. http://dx.doi. org/10.1007/s00705-012-1299-6

Altschul SF, Madden TL, Schäffer AA, Zhang J, Zhang Z, Miller W, Lipman DJ (1997): Gapped BLAST and PSI-BLAST: a new generation of protein database search programs. Nuc. Acid Res. 25, 3389-3402. http://dx.doi.org/10.1093/ nar/25.17.3389

Bandla MD, Campbell LR, Ullman DE, Sherwood JL (1998): Interaction of tomato spotted wilt Tospovirus (TSWV) glycoproteins with a thrips midgut protein, a potential cellular receptor for TSWV. Phytopathology 88, 98-104. http://dx.doi.org/10.1094/PHYTO.1998.88.2.98

Caglar BK, Fidan H, Guldur ME, Elbeaino T (2011): The Prevalence of Three Viruses Infecting Fig in Southern Turkey. J. Phytopathol. 159, 181-183. http://dx.doi.org/10.1111/j.14390434.2010.01749.x

Caglayan K, Serçe ÇU, Barutçu E, Kaya K, Medina V, Gazel M, Soylu S, Çalışkan O (2010): Comparison by sequencebased and electron microscopic analyses of Fig mosaic virus isolates obtained from field and experimentally inoculated fig plants. Plant Dis. 94, 1448-1452. http:// dx.doi.org/10.1094/PDIS-11-09-0771

Chung CT, Niemela SA, Miller RH (1989): One-step preparation of competent Escherichia coli: transformation and storage of bacterial cells in the same solution. Proc. Natl. Acad. Sci. USA 86, 2172-2175. http://dx.doi.org/10.1073/ pnas.86.7.2172

Condit IJ (1955): Fig varieties. A monograph. Hilgardia 23, 323-538.

Elbeaino T, Digiaro M, De Stradis A, Martelli GP (2006): Partial characterization of a closterovirus associated with a chlorotic mottling of fig. J. Plant Pathol. 88, 187-192.

Elbeaino T, Digiaro M, De Stradis A, Martelli GP (2007a): Identification of a second member of the family Closteroviridae in mosaic-diseased figs. J. Plant Pathol. 89, 119-124.

Elbeaino T, Choueiri E, Hobeika C, Digiaro M (2007b): Presence of Fig leaf mottle associated virus 1 and 2 in Lebanese fig orchards. J. Plant Pathol. 89, 409-411.
Elbeaino T, Digiaro M, Alabdullah A, De Stradis A, Minafra A, Mielke N, Castellano MA, Martelli GP (2009): A multipartite single-stranded negative-sense RNA virus is the putative agent of fig mosaic disease. J. Gen. Virol. 90, 1281-1288. http://dx.doi.org/10.1099/vir.0.008649-0

Elbeaino T, Heinoun K, Digiaro M, Martelli GP (2010): Fig mild mottle-associated virus, a novel closterovirus infecting fig. J. Plant Pathol. 92, 165-172.

Elbeainoa T, Digiaroa M, Martelli GP (2011a): Complete sequence of Fig fleck-associated virus, a novel member of the family Tymoviridae. Virus Res. 161, 198-202. http://dx.doi. org/10.1016/j.virusres.2011.07.022

Elbeaino T, Kubaa RA, Digiaro M, Minafra A, Martelli GP (2011b): The complete nucleotide sequence and genome organization of Fig cryptic virus, a novel bipartite dsRNA virus infecting fig, widely distributed in the Mediterranean basin. Virus Genes 4, 415-421. http://dx.doi.org/10.1007/ s11262-011-0581-0

Elbeaino T., Gonzalez Rodríguez AM, Grajal-Martín MJ, Digiaro M (2011c): Survey of fig viruses in the Canary Islands. J. Plant Pathol. 93, 737-739.

Elbeaino T, Digiaro M, Martelli GP (2012): RNA-5 AND -6, two additional negative-sense RNA segments associated with Fig mosaic virus. J. Plant Pathol. 94, 421-425.

Elbeshehy EKF, Elbeaino T (2011): Viruses infecting figs in Egypt. Phytopathol. Medit. 50, 327-332.

Elci E, Ulubas Srce C, Gazel M, Caglayan K (2012): Molecular detection and comparative sequence analysis of viruses infecting fig trees in Turkey. J. Phytopathology 160, 418-423. http://dx.doi.org/10.1111/j.1439-0434.2012.01921.x

Gattoni G, Minafra A, Castellano MA., De Stradis A, Boscia D, Elbeaino T, Digiaro M, Martelli GP (2009): Some properties of Fig latent virus 1, a new member of the family Flexiviridae. J. Plant Pathol. 91, 543-552.

Kimura M (1980): A simple method for estimating evolutionary rate of base substitutions through comparative studies of nucleotide sequences. J. Mol. Evol. 16, 111-120. http:// dx.doi.org/10.1007/BF01731581

Librado P, Rozas J (2009): DnaSP v5: A software for comprehensive analysis of DNA polymorphism data. Bioinformatics 25 , 1451-1452. http://dx.doi.org/10.1093/bioinformatics/ btp187

Luisoni E, Milne RG, Accotto GP, Boccardo G (1987): Cryptic viruses in hop trefoil (Medicago lupulina) and their relationships to other cryptic viruses in legumes. Intervirology 28, 144-156.

Martelli G (2011): Fig mosaic disease and associated pathogens. In Hadidi A, Barba M, Candresse T, Jelkmann W (Eds) Virus and Virus-like Diseases of Pome and Stone Fruits. Minnesota, USA, APS Press, pp. 281-287.

Nei M (1987): Molecular Evolutionary Genetics. Columbia Univ. Press, New York, 512 pp.

Nei M, Kumar S (2000): Molecular Evolution and Phylogenetics. Oxford University Press, New York.

Nouri-Ale Agha G, Rakhshandehroo F, Zamanizadeh HR, Elbeaino T (2013): Presence of Fig fleck-associated virus in fig trees in Iran. J. Plant Pathol. 95, 663. 
Saitou N, Nei M (1987): The neighbour-joining method: A new method for reconstructing phylogenetic trees. Mol. Biol. Evol. 4, 406-425.

Shahmirzaie M, Rakhshandehroo F, Zamanizadeh HR, Elbeaino T (2012): Current Status of Fig Mosaic Disease in Iran. J. Phytopathol. 160, 324-330. http://dx.doi.org/10.1111/ j.1439-0434.2012.01908.x

Tajima F (1989): Statistical method for testing the neutral mutation hypothesis by DNA polymorphism. Genetics 123 , 585-595.

Tamura K, Peterson D, Peterson N, Stecher G, Nei M, Kumar S (2011): MEGA5: molecular evolutionary genetics analysis using maximum likelihood, evolutionary distance, and maximum parsimony methods. Mol. Biol. Evol. 28, 2731-2739. http://dx.doi.org/10.1093/molbev/msr121

Thompson JD, Higgins DG, Gibson TJ (1994): Clustal W: improving the sensitivity of progressive multiple sequence alignment through sequence weighting, positionspecific gap penalties and weight matrix choice. Nucleic Acids Res. 22, 4673-4680. http://dx.doi.org/10.1093/ $\underline{\operatorname{nar} / 22.22 .4673}$

Tsompana M, Aabad J, Purugganan M, Moyer JW (2005): The molecular population genetics of the Tomato spotted wilt virus (TSWV): genome. Mol. Ecology 14, 53-66. http:// dx.doi.org/10.1111/j.1365-294X.2004.02392.x

Walia JJ, Salem NM, Falk BW (2009): Partial sequence and survey analysis identify a multipartite, negative-sense RNA virus associated with fig mosaic. Plant Dis. 93, 4-10. http:// dx.doi.org/10.1094/PDIS-93-1-0004

Walia JJ, Falk BW (2012): Fig mosaic virus mRNAs show generation by cap-snatching. Virology 426, 162-166. http:// dx.doi.org/10.1016/j.virol.2012.01.035 